\title{
Comparison of the therapeutic effects of tri-iodothyronine and methylprednisolone during early sepsis in laboratory animals
}

\author{
Coskun $\mathrm{F}^{1}$, Saylam B ${ }^{1}$, Kulah $\mathrm{B}^{1}$, Dolapci $\mathrm{I}^{2}$, Sungur $\mathrm{A}^{3}$, Vasfi Ozer $\mathrm{M}^{1}$ \\ Ankara Numune Teaching and Research Hospital, Ankara, Turkey. mdbsaylam @yahoo.com
}

\begin{abstract}
Background: Despite major advances, the treatment of sepsis is still a challenging problem for surgeons. This study was aimed to compare the therapeutic effects of methylprednisolone and tri-iodothyronine replacement therapy during an early sepsis.

Material and methods: Forty male Wistar albino rats weighing 300-340g were divided into the Control, CLP, CLP/MP, CLP/T3 and CLP/MP/T3 groups. The Control group underwent a sham operation. Only cecal ligation and puncture was performed in the CLP group. The CLP/MP groups received an intramuscular injection of (MP) methylprednisolone (30 mg/kg) at one and half hour before CLP. The CLP/T3 group was given an intraperitoneal (IP) injection of tyroid hormone (T3) $0.4 \mu \mathrm{g} / 100 \mathrm{~g}$ immediately after CLP. The CLP/MP/T3 group was given IM injection of MP $30 \mathrm{mg} / \mathrm{kg}$ before CLP and IP injection of T3 $0.4 \mu \mathrm{g} / 100 \mathrm{~g}$ after CLP. Hemavet changes, blood cultures, peritoneal bacteria content, hormonal alterations and histopathologic changes of intestinal, lung and liver tissue were used to asses the possible therapeutic effects of MP and T3 during early sepsis.

Results: A septic insult resulted in significant alterations on hemavet values, free T3, free T4 and cortisol levels, peritoneal bacteria content and intestinal lung and liver tissue samples of the CLP group. Hemavet changes and peritoneal inflammation findings were significantly limited in the CLP/T3 and CLP/MP/T3 groups. Histopathologic changes had no significant difference between the groups during an early sepsis.

Conclusion: Compared to the MP replacement therapy, therapeutic effects of T3 replacement therapy have been found significantly more promising (Tab. 1, Fig. 10, Ref. 49). Full Text in PDF www.elis.sk.

Key words: tri-iodothronine, methylprednisolone, early sepsis.
\end{abstract}

Despite advances in systemic antibiotics and aggressive surgical intervention, septic shock and multiorgan failure resulting from sepsis continue to be the most common cause of death in surgical intensive care units. Over the past 20 years a large number of clinical trials in septic patients have been performed. In these trials, a variety of therapeutic agents for sepsis have been evaluated, based largely on progress in the understanding of the pathophysiology of sepsis (1-3).

The use of corticosteroids has undergone a re-evaluation after the recognition of the adrenal insufficiency in septic patients. Recent reports in literature suggest that the treatment of specific populations of septic patients with corticosteroid supplementation provide a survival advantage in critically ill patients (4-7).

There is also a vast literature on the changes in thyroid function tests that occur during non-thyroidal illness such as sepsis. The changes are defined as a decreased concentration of plasma tri-iodotyronine with normal or low thyroxine. Therapy with thyroid hormone as either thyroxine or tri-iodothyronine has been

${ }^{1}$ Ankara Numune Teaching and Research Hospital, Ankara, Turkey, ${ }^{2}$ Medicine Faculty of Ankara University, Microbiology Clinic, Ankara, Turkey, and ${ }^{3}$ Medicine Faculty of Hacettepe University, Pathology Department, Ankara, Turkey

Address for correspondence: F. Coskun, MD, 84. Sokak 3/6 06500, Bahcelievler, Ankara, Turkey.

Phone: +90.312 .2120232 , Fax: +90.312 .3103460$ suggested for patients with sepsis, cardiac disease, pulmonary disease or severe infection (8-12).

This study aimed to evaluation and comparison of the effects of methylprednisolone and tri-iodthyronine replacement therapy during an early sepsis.

\section{Methods}

\section{Experimental model of polymicrobial sepsis}

The experiments described herein conform to the NIH Guidelines for the Care of Laboratory Animals and were approved by the ethic committee. Adult male Wistar Albino rats (300-340g) were fasted overnight before the induction of sepsis but allowed water and libitum. The rats were anesthetized with an intramuscular injection of ketamin $(50 \mathrm{mg} / \mathrm{kg})$ and xylazine $(5 \mathrm{mg} / \mathrm{kg})$ and randomized to five groups including the control, cecal ligation and puncture (CLP), CLP with methylprednisolone treatment (CLP/ /MP), CLP with tri-iodothyronine treatment (CLP/T3) and CLP with methylprednisolone and tri-iodothyronine combined treatment (CLP/MP/T3). There were eight animals in each group. Wichterman (13) model was performed as a CLP model. A 2-cm midline incision was made and the cecum was ligated with $4 / 0$ silk just distal to the ilececal valve to avoid intestinal obstruction. The cecum was punctured twice with a 18-gauge needle on the antimesenteric side and the bowel was gently squeezed to extrude 
Table 1. Simon's Peritoneal Inflammation Grading

\section{Grade 0 No Inflammation}

Grade I Well walled off abscess, no free peritoneal fluid

Grade II Walled-off abscess, small amount of free peritneal fluid and patchy areas of cecal wall necrosis.

Grade III Poor localization of the inflammatory proces, moderate amount of free peritoneal fluid and gangrenous cecum.

Grade IV No walling off of the cecum, large amount of free hemorrhagic fluid in the peritoneal cavity, and extensive gangrene and hemorrhagic fluid in the cecal wall.

a small amount of fecal material and returned to abdominal cavity. The control groups underwent a sham laparatomy. The treatment group (CLP/MP) received an intramuscular injection of methylprednisolone $\left(30 \mathrm{mg} / \mathrm{kg}\right.$ Prednol ${ }^{\circledR}$, Mustafa Nevzat Turkey) at one and half hour preoperatively. The treatment group (CLP/T3) received an intraperitoneal injection of tyroid hormone $(0.4 \mu \mathrm{g} / 100$ g Thyrotardin ${ }^{\circledR}$ Inject N Henning Berlin GMBH Germany) immediately after CLP. The combined treatment group (CLP/MP/T3) received an intramuscular injection of methylprednisolone (30 mg/ $\mathrm{kg}$ Prednol $($, Mustafa Nevzat) at one and half hour preoperatively and an intraperitoneal injection of tyroid hormone $(0.4 \mu \mathrm{g} / 100 \mathrm{~g}$ Thyrotardin ${ }^{\circledR}$ Inject N Henning Berlin GMBH Germany) immediately after CLP. The abdominal incision was closed in two layers.

Immediately after surgery, each rat received a subcutaneous injection of $1 \mathrm{ml}$ saline and an intramuscular injection of İmipenem $(15 \mathrm{mg} / \mathrm{kg})$. The rats were put into cages until postopeative sixth hour. At sixth hour after CLP or sham operation the animals were anesthetized again with an intramuscular injection of ketamin (50 $\mathrm{mg} / \mathrm{kg}$ ) and xylazine $(5 \mathrm{mg} / \mathrm{kg})$

\section{Evaluation of Peritoneal Inflammation and Peritoneal Bacteria Content}

At the end of sixth hour a re-laparatomy was performed on all rats and the degree of peritoneal inflammation was assessed according to Simon's (14) method (Tab. 1). Later, peritoneal lavage was performed with $4 \mathrm{ml}$ of normal saline. Next $50 \mu \mathrm{l}$ of this fluid was incubated in blood agar and Mc Conkey's agar at $37^{\circ} \mathrm{C}$ for 24 hours. Peritoneal bacteria content was evaluated and described as colony forming units per mililiter $(\mathrm{CFU} / \mathrm{ml})$.

\section{Determination of hemavet changes and hormon levels}

Blood samples were obtained by intracardiac puncture, some of these samples were analyzed by automated (Beckman-Coulter T-890®) differential cell counting immediately following a specimen collection. Some of intracardiac blood samples were used to determine serum freeT3, freeT4 and cortisol hormon levels. Thyroid hormone levels were measured by using Architecht free T3 or Architecht free T4 kits in Architecht I-2000® analyzer, cortisol levels were measured by using Elecsys Cortisol CalSet (Roche ${ }^{\circledR}$ diagnostics Gmbh) kits in Elecsys2010® analyzer.

\section{Preparation and evaluation of blood cultures}

A $1 \mathrm{ml}$ sample of blood from each animal was immediately placed into a biphasic blood culture medium containing Brain Hearth Infusion (BHI) broth and BHI agar and incubated at $37^{\circ} \mathrm{C}$ for 18-24 hours under aerobic conditions. After incubation from all culture materials, subsequent subcultures were performed on blood agar and Mc Conkey agar. All subcultures were incubated under aereobic conditions and were examined at 18-24 hour for presence of growth. The identification of bacterial species was performed by standard microbiological methods.

\section{Determination of histopathologic changes}

During scarification, terminal ileum, left hepatic lobe and left lung lobe tissue samples were removed from each animal for determination of histopathologic changes. Paraffin sections were stained with hematoxylin and eosin stain. Pathologist examined all specimens in a blinded fashion. The tissue sections were observed and photographed on a research microscope for each experimental animal.

\section{Statistical analysis}

Data analysis was performed using a statistical software program, SPSS for Windows.11.0. Kruskal-Wallis, Mann-Whitney-U and one-way analysis of variance (Tukey post hoc) tests were employed and the differences were considered significant at $\mathrm{p}$ value $<0.05$.

\section{Results}

Intraperitoneal macroscopic findings were assessed as Grade 0 in the control animals whereas Grade III and IV intraperitoneal inflammatory alterations were recorded in CLP animals (25\% and $75 \%$ respectively). Grade III (75\%) and grade IV (25\%) intraperitoneal inflammation findings were also observed in CLP/MP treatment groups. CLP/T3 and CLP/MP/T3 treatment groups had no grade IV intraperitoneal inflammation findings. Intraperitoneal inflammatory alterations were significantly limited in CLP/T3 and CLP/MP/T3 treated rats compared to septic (CLP) and metylprednisolon treated (CLP/MP) animals $(\mathrm{p}<0.05$ and $\mathrm{p}<0.007$ respectively). There was no significant difference between the CLP/T3 and CLP/MP/T3 animals regarding intraperitoneal inflammatory alterations.

The peritoneal bacteria contents of the study groups are detailed in Fig. 1. As compared to the control group, the bacterial

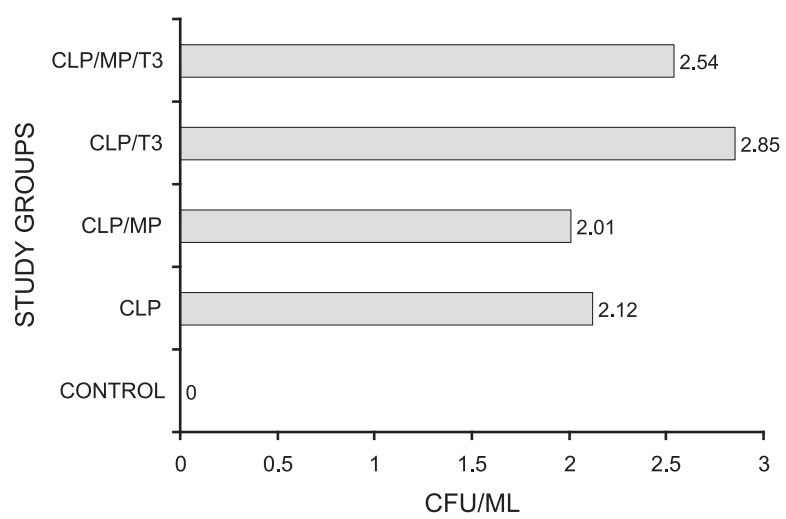

Fig. 1. Bacteria content of peritoneal lavages of the groups at $6 \mathrm{~h}$ after clp. 


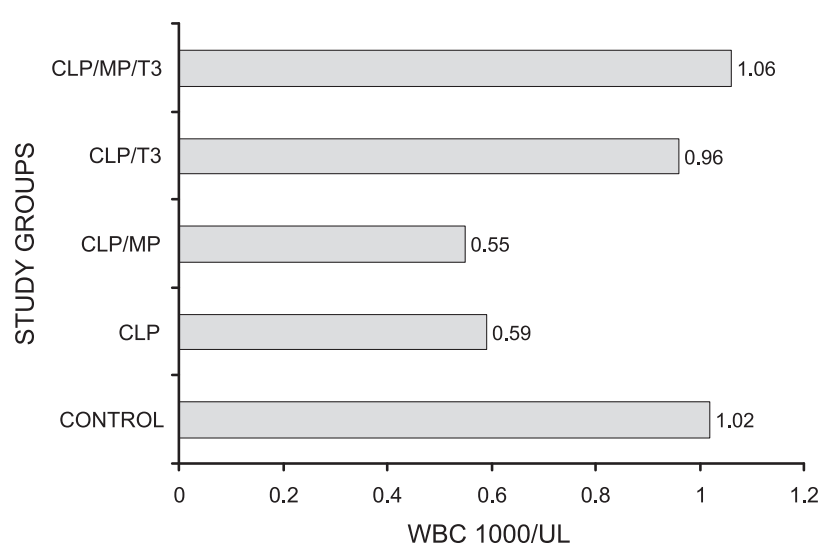

Fig. 2. White Blood Cell levels at 6 hour after clp.

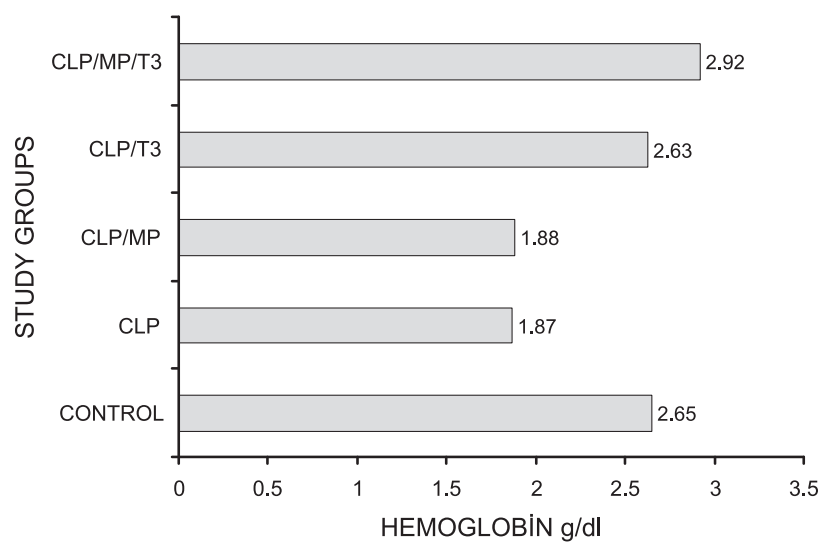

Fig. 3. Hemoglobin levels at 6 hour after clp.

contents of the peritoneal lavages of CLP and the other groups were found significantly increased at six hours after CLP. There was no statistically significant difference in the bacterial contents of peritoneal lavages of these groups. Blood cultures of all control animals were negative. Blood cultures were found positive in three ( $40 \%)$ of CLP group animals, one (25\%) of CLP/MP treated animals, 4 (50\%) of CLP/T3 treated animals and in $4(50 \%)$ of $\mathrm{CLP} / \mathrm{MP} / \mathrm{T} 3$ treated animals.

As shown in Figure 2, septic insult resulted in a significantly decreased white blood cell (WBC) count in CLP $\left(0.59 \times 10^{3} / \mu 1\right)$ and CLP/MP $\left(0.55 .10^{3} / \mu 1\right)$ treated animals when compared to those $\left(1.02 \times 10^{3} / \mu 1\right)$ of control animals $(\mathrm{p}=0.022$ and $\mathrm{p}=0.013$ respectively). WBC counts were significantly elevated in CLP/T3 $\left(0.96 \times 10^{3} /\right.$ $\mu 1)$ and CLP/MP/T3(1.06 $\left.\times 10^{3} / \mu 1\right)$ treated animals compared to levels in septic (CLP) animals ( $\mathrm{p}=0.047$ and $\mathrm{p}=0.013$ respectively). White Blood Cell counts had no significant differences between the CLP/T3 and CLP/MP/T3 treated animals.

Hemoglobin values were found significantly low in septic $(1.87 \mathrm{~g} / \mathrm{dl})$ and CLP/MP $(1.88 \mathrm{~g} / \mathrm{dl})$ animals compared to the values $((2.65 \mathrm{~g} / \mathrm{dl})$ of control animals $(\mathrm{p}=0.004$ and $\mathrm{p}=0.005$ respectively). In contrast, the hemoglobin values of CLP/T3 (2.63 g/dl) and CLP/MP/T3 $(2.92 \mathrm{~g} / \mathrm{dl})$ treated animals were significantly ( $p=0.005$ and $p=0.001$ respectively) higher than the values of CLP

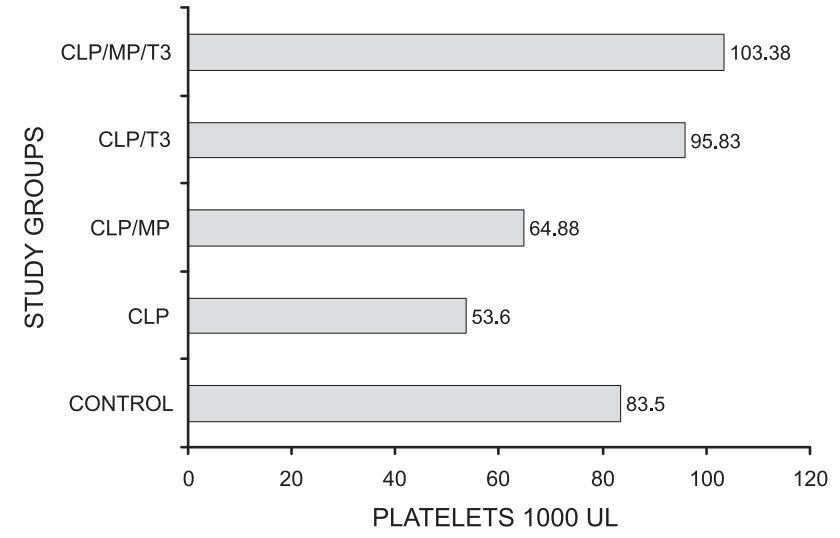

Fig. 4. Platelet levels at 6 hour after clp.

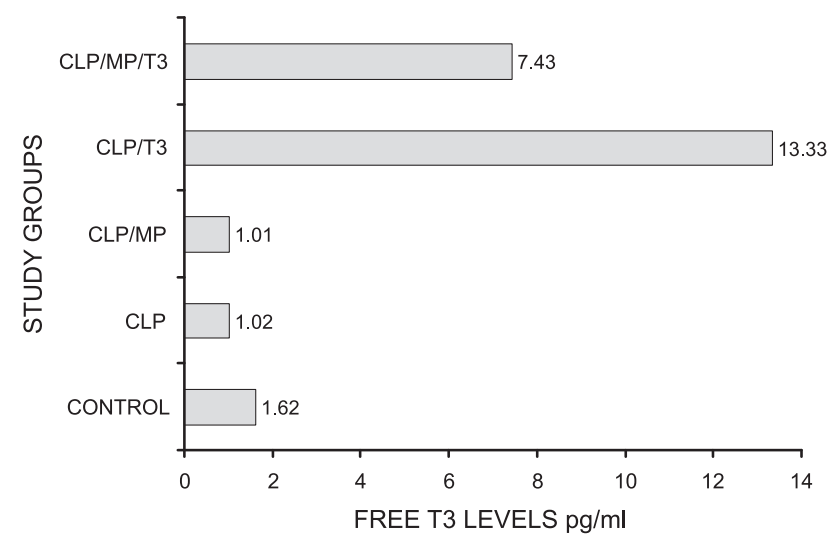

Fig. 5. Free T3 levels at 6 hour after clp.

animals. Additionally, hemoglobin values of CLP/T3 treated animals were also significantly $(\mathrm{p}=0.006)$ higher than those of CLP/ MP treated animals (Fig. 3).

The platelet counts of the groups are shown in the Fig. 4. There was a significant decrease in the platelet count in CLP $\left(53.60 \times 10^{3} /\right.$ $\mu \mathrm{l})$ and $\mathrm{CLP} / \mathrm{MP}\left(64.88 \times 10^{3} / \mu \mathrm{l}\right)$ treated animals compared to those $\left(83.50 \times 10^{3} / \mu 1\right)$ of control $(\mathrm{p}=0.002$ and $\mathrm{p}=0.047$ respectively). The platelet count of CLP/T3 $\left(95.83 \times 10^{3} / \mu 1\right)$ and CLP/MP/T3 $\left(103.38 \times 10^{3} / \mu 1\right)$ treated animals were significantly higher than those of CLP and CLP/MP treated animals.

The mean serum free T3 (FT3) concentrations in CLP group $(1.02 \mathrm{pg} / \mathrm{ml})$ were decreased significantly $(\mathrm{p}=0.004)$ compared to control rats $(1.62 \mathrm{pg} / \mathrm{ml})$ at six hours. As compared to the septic (CLP) group, the mean serum FT3 concentrations were significantly high in both CLP/T3 $(13.33 \mathrm{pg} / \mathrm{ml})$ and CLP/MP/T3 $(7.43 \mathrm{pg} / \mathrm{ml})$ treated groups $(\mathrm{p}<0.001$ and $\mathrm{p}<0.001$ respectively). The mean serum FT3 concentrations are detailed in the Fig. 5.

The mean serum free T4 (FT4) concentrations are shown in Fig. 6. There were no differences between the serum FT4 levels of CLP group and those of control groups. CLP/MP treated animals had significantly low serum FT4 concentrations compared to the CLP and control animals $(p<0.001$ and $p=0.009$ respectively). 


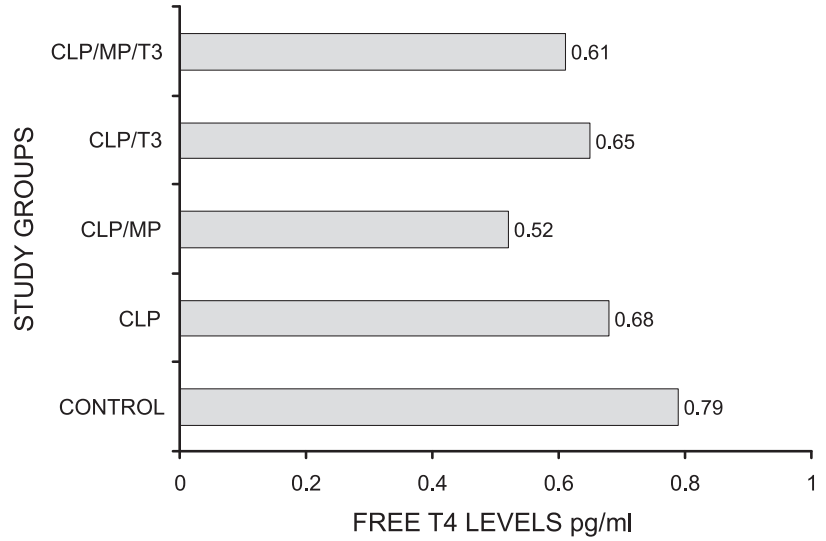

Fig. 6. Free T4 levels at 6 hour after clp.

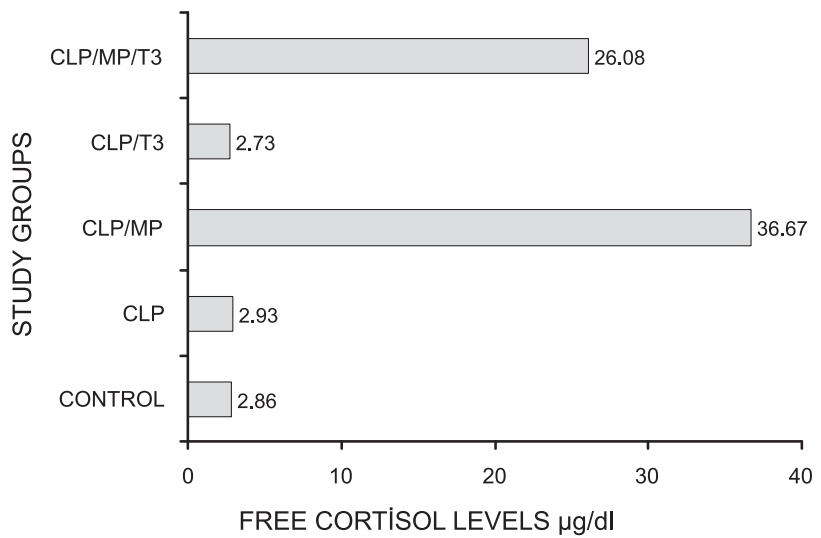

Fig. 7. Free cortisol levels at 6 hour after clp.

The mean serum cortisol levels were similar in the control $(2.86 \mu \mathrm{g} / \mathrm{dl})$, CLP $(2.93 \mu \mathrm{g} / \mathrm{dl})$ and CLP/T3 $(2.73 \mu \mathrm{g} / \mathrm{dl})$ treated animals. Metylpredisolon replacement treatment resulted in markedly elevated serum cortisol levels in CLP/MP $(36.67 \mu \mathrm{g} / \mathrm{dl})$ and CLP/MP/T3 (26.08 $\mu \mathrm{g} / \mathrm{dl})$ treated groups as expected (Fig. 7).

Intestinal tissue architecture was well preserved in control animals (Fig. 8a). Villous pattern showed some alterations in the other groups. Necrosis of villous tip was noted in one of CLP animals, 2 (25\%) of CLP/MP treated animals, one of CLP/T3 treated animals and in $2(25 \%)$ of CLP/MP/T3 treated animals (Fig. $8 b)$. CLP, CLP/MP, CLP/T3 and CLP/MP/T3 treated animals had no significant difference regarding to the infiltration of the inflammatory cells and the edema of the villi at six hour after CLP.

There was a severe congestion of the liver in all group animals. Portal inflammatory cell infiltration in liver tissues were observed in CLP, CLP/T3 and CLP/MP/T3 group animals (Fig. 9a). CLP/ MP treated animals have significantly limited portal inflammatory cell infiltration (Fig. 9b). The histopathologic alterations in liver tissue had no significant difference between the groups.

CLP resulted in distinct congestion, alveolar edema and some emphysematous changes during early sepsis (Fig. 10). Animals in CLP and other treatment groups had no significant difference regarding to histopatologic alterations in lung tissue samples.

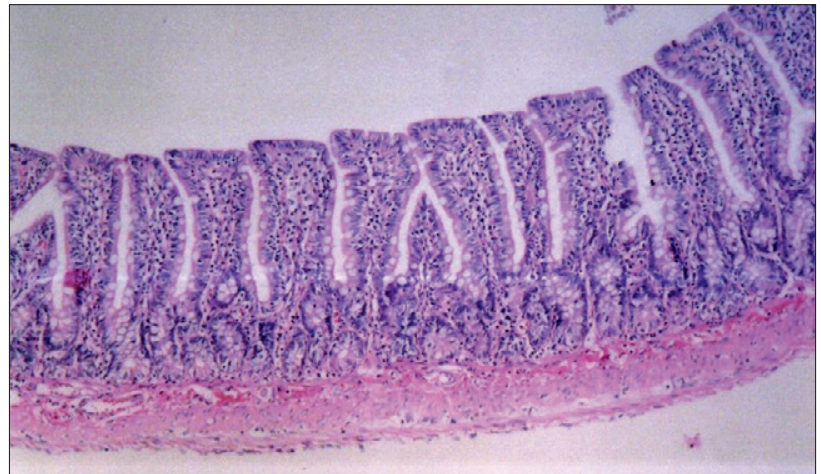

Fig. 8a. Normal epithelium.

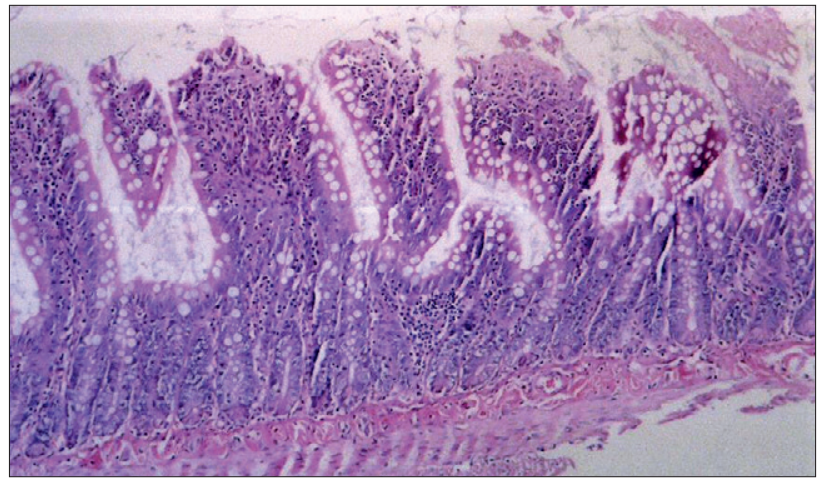

Fig. 8b. The tip necrosis of villi.

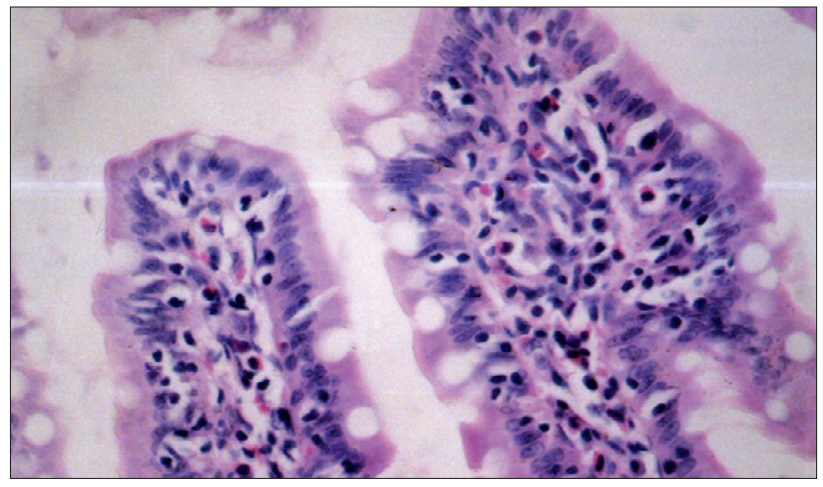

Fig. 8c. Inflammatory cell infiltration of the epithelium.

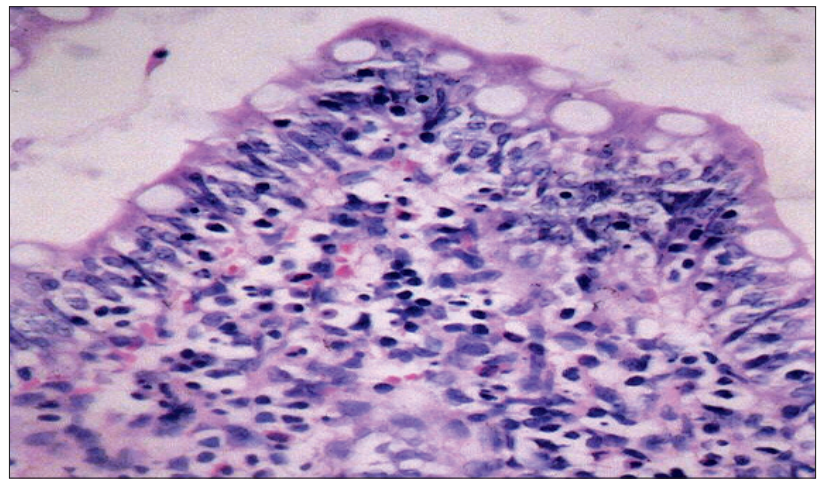

Fig. 8d. Massive inflammatory cell infiltration. 


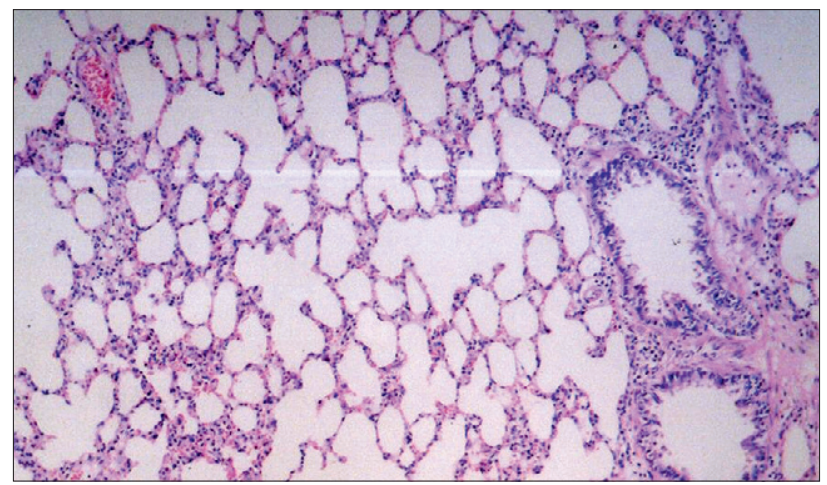

Fig. 9a. Normal lung tissue.

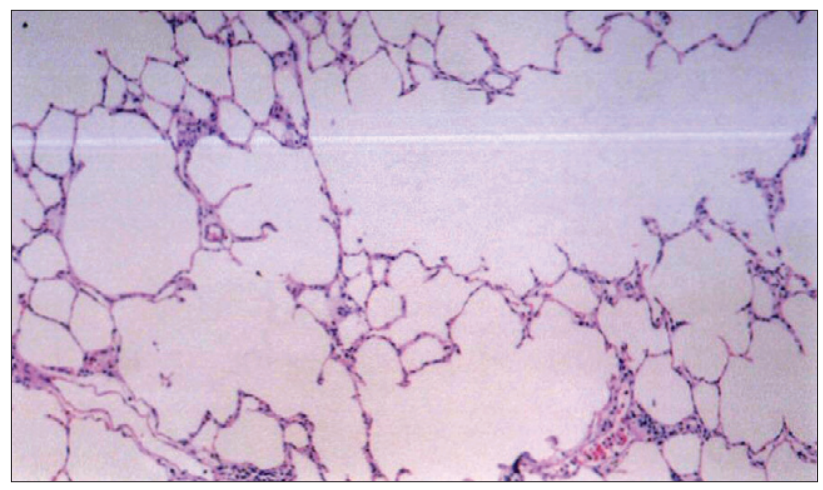

Fig. 9b. Minimal emphysema.

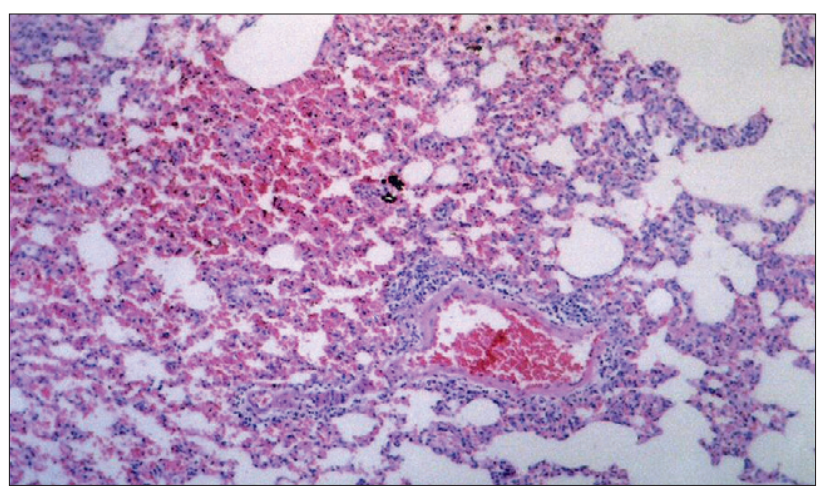

Fig. 9c. Congestion.

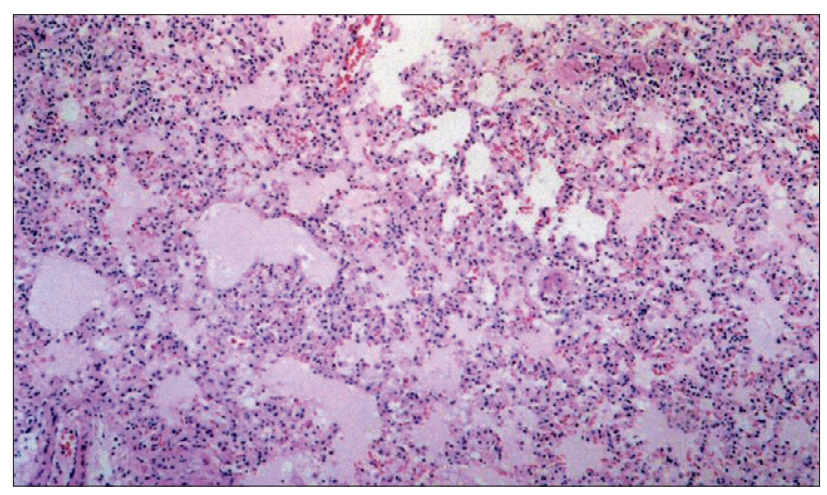

Fig. 9.d. Edema.

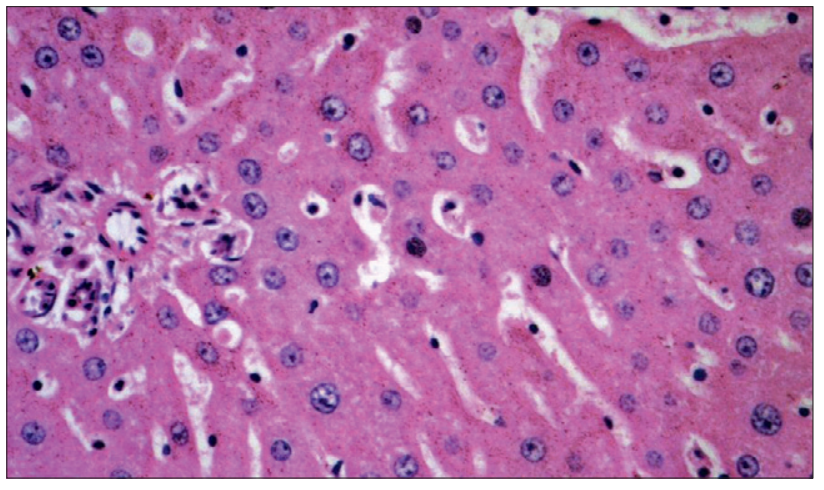

Fig. 10a. Normal liver tissue.

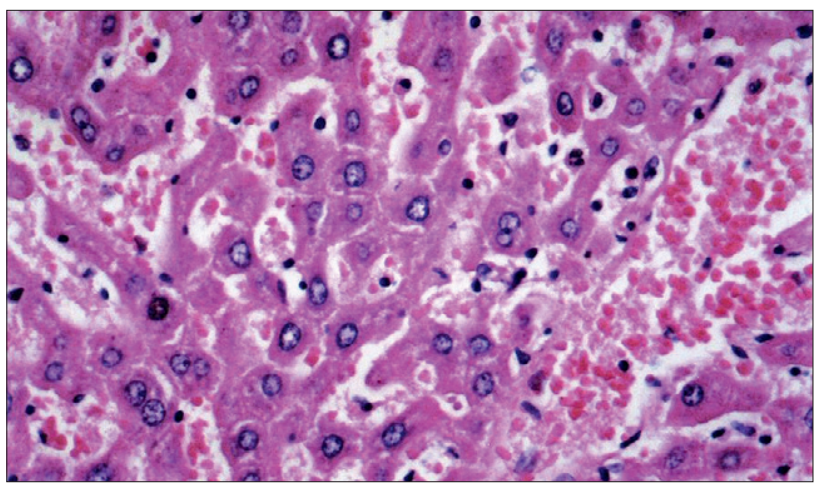

Fig. 10b. Widespread congestion.

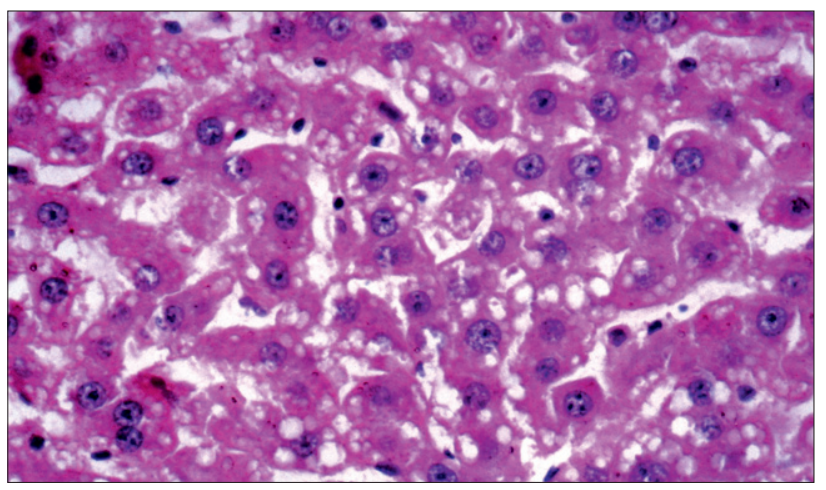

Fig. 10c. Widespread vacuolar degeneration.

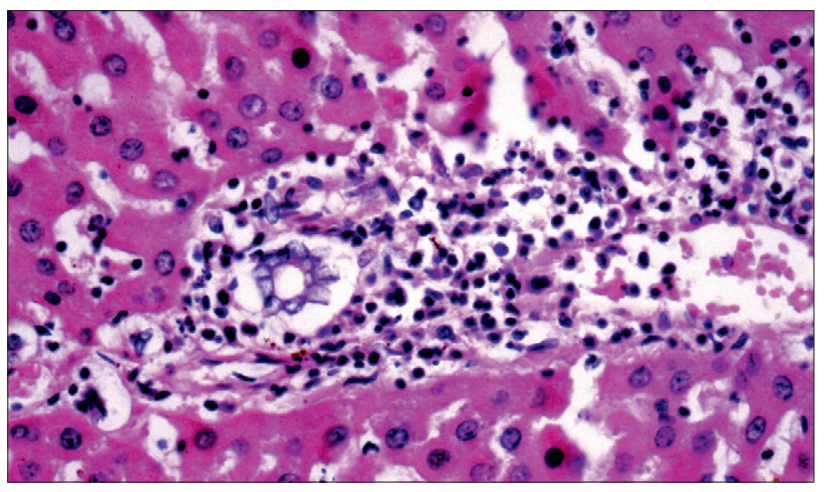

Fig. 10d. Inflammatory cell infiltration of the portal field. 


\section{Discussion}

Despite the advances in critical medicine, the management of the patients with severe sepsis is usually supportive rather than therapeutic. The failure of clinical trials with promising immunomodulatory agents seems to be related with the flawed or inappropriate animal models. Animal studies also failed to reproduce the cardiopulmonary and metabolic responses seen in clinical practice. The confirmation of the efficacy of potential therapeutic agents from simple animal studies to clinical trials comprises another challenging problem. Therefore the more realistic animal models are a prerequist for the more comparable results $(1,3)$.

In this study, we performed CLP experimental polymicrobial sepsis model because it resembles the clinical situation of bowel perforation, inducing peritonitis due to mixed intestinal flora(15). In this model, initial hyperdynamic phase is characterized by an increased cardiac output, tissue perfusion and decreased total peripheral resistance. This is followed by late, hypodynamic phase, characterized by reduced cardiac output and microvascular blood flow in various tissues (16). Our study scopes and compares the hematologic, hormonal and histopathologic alterations during early hyperdynamic phase.

Hiramatsu et al showed inflammatory changes in the cecum at $3 \mathrm{~h}$ and the collection of purulent peritoneal fluid within $12 \mathrm{~h}$ following CLP with a 25 gauge needle (17). In our study, significant inflammatory changes were established in the cecum with purulent peritoneal fluid collection in CLP group animals at $6 \mathrm{~h}$ after CLP with a 18 gauge needle. Both blood cultures and peritoneal lavage cultures defined the nature of the inflammation as polymicrobial sepsis in the CLP treated animals.

It has been suggested that sepsis is characterized by leucocytosis or leucopenia, isolated thrombocytopenia, and decreased hemoglobin values, however there is no specific laboratory dependent criteria for diagnosis (18). Particularly thrombocytopenia may be an early indicator of gram-negative sepsis in pediatric and burned patients (19). In our study, significant leukopenia, thrombocytopenia and decreased hemoglobin values were noted in CLP group animals at $6 \mathrm{~h}$ after CLP. The hematologic changes were consistent with those observed in animals with polymicrobial sepsis of the previous experimental studies.

Previous trials have clearly demonstrated that sepsis activates the Hypothalamic-Pituitary-Adrenal axis to release corticotropin and glucocorticoid hormones $(20,21)$. Cortisol plays a vital supportive role in the maintenance of vascular tone, endothelial integrity, vascular permeability and the distribution of total body water within the vascular compartment and also enhances the vasoconstrictor actions of catecholamines. It has been shown that an increase in the half-life of cortisol occured during septic shock whereas adrenalectomy reduced the tolerance of animals to experimentally induced septic shock. It is obvious that normal adrenal gland function and increased plasma cortisol levels are important and necessary for the protection of homeostatic response (22-24). Although control and CLP animals have no significant differences in plasma cortisol levels at $6 \mathrm{~h}$ after CLP, we measured markedly decreased plasma cortisol levels in the CLP group animals at 48 $\mathrm{h}$ after CLP in our second part of study.
Sepsis also influences the hypothalamic pituitary thyroid axis by decreasing the circulating levels of T3. This functional hypothyroidism is characterized by a low serum T3 level, a normal or low serum T4 level and normal TSH level. This syndrome is collectively referred to as euthyroid sick syndrome. Previous studies showed that intact thyroid functions are essential for survival from shock and T3 supplementation improves mortality rates in hypothyroid animals. The degree of decreasing levels of T3 is closely related to prognosis (25-27). Our study showed that CLP resulted in significantly decreased T3 levels at $6 \mathrm{~h}$ after CLP. The animals receiving T3 treatment exhibited more improved hematologic parameters and significantly limited intraperitoneal inflammation findings. The improvements in hematologic parameters and limitation of intraperitoneal inflammation findings in T3 treated animals are explained by preservation of cellular and humoral immunity. Previous experimental studies demonstrated that surgically or chemically induced thyroid hormone depletion resulted in significantly decreased cellular and humoral immunity. Conversely, thyroid hormone repletion enhances both types of immunity $(28,29)$.

Though, there is still considerable controversy concerning the use of corticosteroids in the treatment of severe sepsis. Corticosteroids have antinflammatory and immunosupressive effects and also inhibit the synthesis of IL-1, IL-6, IL- 8 and TNF- $\alpha$. Bone et al reported that corticosteroids had beneficial effects when they had been administered before or as early as possible after the insult. Low-dose glucocorticoids exerted their positive effects by means of stabilization of lysosomal and cell membranes, inhibition of complement-induced granulocyte aggregation, improved myocardial performance and improvement in metabolic defects. Low-dose glucocorticoids also reduced the requirement of vazopressors in management of septic shock (30-32). The data from this study failed to demonstrate that corticosteroid replacement therapy had an effect on the improvement of hemavet changes and limitation of peritoneal inflammation during early experimental sepsis. However, the platelet counts have been noted slightly high in this replacement group when compared to the septic group animals.

Reports are found in literature that activation of coagulation occurs in experimental sepsis models. Activation of clotting and fibrinolytic pathways resulted in the consumption of platelets and coagulation factor concentrations. Antithrombin III (ATIII) inhibits the clotting cascade and also reduces the inflammatory response (33-37). Chapital et al. reported that T3 supplementation reduced the sepsis-induced decrease in ATIII levels (28). Our data showed that T3 administration significantly increased the platelet counts and limited the intraperitoneal inflammatory changes.

In our study, the spectrum of bacteria isolated from blood and peritoneal lavage cultures were in line with the previous reports. In the current study, the metabolic and histopathologic alterations were not parallel with the results of blood or peritoneal lavage cultures. However, there was no significant difference in bacteria content of the blood and peritoneal lavage of the CLP treated and replacement groups $(31,38)$. These findings were found compatible with the thesis of 'The development of shock was not related o the presence or absence of a positive blood culture'. 
Pulmonary dysfunction is the end organ response of the lung to a septic insult and defined as adult respiratory distress syndrome (ARDS). A variety of pathophysiologic mechanisms have been shown to play a role in the pathogenesis of ARDS. Salkowski et al. showed dramatic increases in lung proinflammatory and antiinflammatory cytokines and chemokines during the early phase of polymicrobial sepsis. Schwartz et al. reported that the activation of nuclear factor $\kappa \mathrm{B}(\mathrm{NF} \kappa \mathrm{B})$ in alveolar macrophages is an important step in the pathophysiology of ARDS. It is also known that a decrease in lung compliance and alterations in type- 2 cellular function occur during sepsis. Inflammatory cell activation and, in particular neutrophil activation, also plays an important role in the pathogenesis of sepsis-induced ARDS (39-41). In the current study, CLP induced polymicrobial sepsis caused a widespread alveolar edema and congestion at $6 \mathrm{~h}$ after CLP. Histologic examinations of the lungs of the T3 treated animals exhibited minimal alveolar edema. Many authors have examined the effects of T3 administration on pulmonary function in sepsis. Improvement in respiratory drive, pulmonary histologic integrity and surfactant availability have been found in this trials $(42,43)$. The mechanism for this improvement could be attributed to the maintenance of type-2 cellular function and diminishing the inflammatory response by preservation of ATIII levels. There was no significant improvement in sepsis induced histopathologic alterations in the lungs of the rats receiving MP treatment during an early phase of the polymicrobial sepsis.

Chaudry et al demonstrated that hepatocellular dysfunction occured during the very early stage of polymicrobial sepsis. The Kupffer cells derived proinflammatory cytokines IL-1 $\beta$ and IL-6 appeared to be directly or indirectly responsible for producing hepatocellular dysfunction during early sepsis $(44,45)$. In this study, CLP resulted in markedly histopathologic changes defined as congestion, dilatation of the portal sinusoids and infiltration of the inflammatory cells during early sepsis. Histologic evaluation of the liver tissues of the MP-treated animals revealed a preservation of normal architecture of the sinusoids and minimal congestion. This improvement in hepatocellular tissue in MP-treated animals could be explained by decreasing IL- $1 \beta$ and IL- 6 synthesis. Gloor et al demonstrated that glucocorticoids blocked IL-1 $\beta$ and IL-6 synthesis by interfering with the transcription of the cytokine gene (46).

Our study showed that the animals receiving T3 treatment also exhibited a well preserved liver tissue architecture at 6 hours after CLP. When we compared the protective effects of T3 and MP on CLP-induced histopathologic alterations in the liver, T3 replacement therapy seemed to be more protective regarding the congestion of liver. Histologic examination of the livers of the MP treated animals exhibited a significantly decreased infiltration of inflammatory cells in portal sinusoids. Nagaya et al. reported that activation of NFאB played an important role in immune and inflammatory responses by controlling gene expression of several cytokines. The activation of NFאB byTNF- $\alpha$ may be responsible for pathogenesis of euthyroid sick syndrome (47).

Previous experimental studies showed that the intestinal tissue seemed to be more vulnerable during the late stage of sepsis. CLP induced sepsis caused minimal intestinal histopathologic changes during early period in this study. Yang et al showed marked intes- tinal histopathologic changes at $21 \mathrm{~h}$ after $\operatorname{CLP}(48,49)$. We had no significant histopathologic alterations in the intestinal tissues of the rats given replacement therapy or CLP treated.

In this study, the rats administered MP and T3 combined replacement therapy had significantly higher serum T3 levels whereas the serum T4 levels were normal. As compared to the T3 replacement group, serum T3 levels were found slightly lower in the rats receiving MP/T3 combined replacement therapy. These findings could be attributed to a decreased conversion of T4 to T3 in the presence of cortisol. Although it had no superiority regarding only T3 replacement therapy, combined MP/T3 hormone replacement therapy caused significant improvements in CLP induced hemogram changes and histopathologic alterations.

\section{Conclusion}

In conclusion, this study showed that CLP induced polymicrobial sepsis resulted in hemogram changes, histopatologic alterations in liver and lung tissues and also hormonal changes defined as euthyroid sick syndrome. We suggest that both $\mathrm{T} 3$ replacement therapy and MP/T3 combined replacement therapy have significant protective and healing effects on the hematologic and histopathologic derangements which occur during early polymicrobial sepsis. The inflammatory response can be controlled and effectively limited by using T3 replacement therapy during an early sepsis.

\section{References}

1. Parker SJ, Watkins PE. Experimental models of gram negative sepsis. Brit J Surg 2001; 88 (1): 22-30.

2. Yang S, Koo DJ, Chaudry IH, Wang P. The important role of the gut in initiating the hyperdynamic response during early sepsis. J Surg Res 2000; 89 (1): 31-37.

3. Glück T, Opal SM. Advances in Sepsis Therapy. Drugs 2004; 64 (8): 837-859.

4. Koo DJ, Jackman D, Chaudry IH, Wang P. Adrenal insufficiency during the late stage of polymicrobial sepsis. Crit Care Med 2001; 29 (3): 618-622

5. O'Brien JM Jr, Abraham E. New approaches to the treatment of sepsis. Clin Chest Med 2003; 24 (4): 521-548.

6. Minneci PC, Deans KJ, Banks SM, Eickhacker PQ, Natanson C. Meta-Analysis: The effect of stereoids on survival and shock during sepsis depends on the dose. Ann Int Med 2004; 141 (1): 47-56.

7. Burry LD, Wax RS. Role of corticosteroids in septic shock. Ann Pharmacother 2004; 38 (3): 464-472.

8. Stathatos N, Levetan C, Burman KD, Wartofsky L. The controversy of the treatment of critically ill patients with thyroid hormone. Best Pract Clin Endocrinol Metab 2001; 15 (4): 465-478.

9. Zaloga G, Chernoww B, Smallridge RC et al. Longitudinal evalution of thyroid function in critically ill surgical patients. Ann Surg1985; 201 (4): 456-464.

10. Little JS. Effect of thyroid hormone supplementation on survival after bacterial infection. Endocrinology 1985; 117 (4): 1431-1436.

11. Brent GA, Hershman JM. Thyroxine therapy in patients with severe nonthyroidal illnesses and low serum thyroxine concentration. J Clin Endocrinol Metab 1986; 63 (1): 1-8. 
12. Reichert MG, Verzino KC. Triiodothyronine supplementation in patients undergoing cardiopulmonary bypass. Pharmacotherapy 2001; 21 (11): 1368-1374.

13. Wichterman KA, Baue AE, Chaudry IH. Sepsis and septic shock: A review of laboratory models and a proposal. J Surg Res 1980;29 (2): 189-201.

14. Simon R, Wetzel N, Winsey K, Levenson SM, Demetriou AA. Suplemantal dietary tyrosine in sepsis and acute hemoragic shock. Arch Surg 1987; 122 (1): 78-81

15. Ebong SJ, Call DR, Bolgos G, Newcomb DE, Granger JI, O’Reilly M, Remick DG. Immunopathologic responses to nonlethal sepsis. Shock 1999: 12 (2): 118-126.

16. Shaolong Y, William GC, Kirby IB, Irshad HC. Differental alterations in systemic and regional oxygen delivery and consumption during the early and late stages of sepsis. J Trauma 1999; 47 (4): 706-712.

17. Hiramatsu M, Hotchkiis RS, Karl IE, Buchmann TG. Cecal ligation and puncture induces apoptosis in thymus, spleen, lung, and gut by an endotoxin and TNF independent pathway. Shock 1997: 7 (4): 247-253.

18. Niels CR, Ren-Fen G, Peter AW. The enigma of sepsis. J Clin Invest 2003; 112 (4): 460-467.

19. Barber A, ShiresIII GT, Shires GT. Shock. In Schwartz SI, Shires GT, Spencer FC, Daly JM, Fischer JE, Galloway AC (Eds). Principles of Surgery. 7th edition volume 1; 1999: 101-122.

20. Williamson DR, Lapointe M. The hypotalamic-pituitary- adrenal axis and low-dose glucocorticoids in the treatment of septic shock. Pharmacoteraphy $2003 ; 23$ (4): 514-525.

21. Mönig H, Arendt T, Meyer M, Kloehn S, Bewig B. Activation of the hypothalamo- pituitary-adrenal axis in response to septic or non-septic diseases-implications for the euthyroid sick syndrome. Intensive Care Med 1999; 25 (12): 1402-1406.

22. Sprung CL, Caralis PV, Marcial EH et al. The effects of high-dose corticosteroids in patients with septic shock. A prospective, controlled study. N Engl J Med 1984311 (18): 1137-1143.

23. Lamberts SW, Bruining HA, de Jong FH. Corticosteroid therapy in severe illness. N Engl J Med 1997; 337 (18): 1285-1292.

24. Schein RM, Sprung CL, Marcial E, Napolitano L, Chernow B. Plasma cortisol levels in patients with septic shock. Crit Care Med 1990; 18 (3): 259-263.

25. Dulchavsky S, Kennedy P, Geller E, Maitra SR, Foster WM, Langenbeck EG. T3 preserves respiratory function in sepsis. J Trauma 1991; 31 (6): 753-759.

26. Sumita S, Ujike Y, Namiki A et al. Supression of the thyrotropin response to thyrotropin-releasing hormone and its association with severity of critical illness. Crit Care Med 1994; 22 (10): 1603-1609.

27. Umpierrez GE. Euthyroid sick syndrome. South Med J2002;95(5):506-513.

28. Chapital AD, Hendrick SR, Lloyd L, Pieper D. The effects of triiodothyronine augmentation on antithrombin III levels in sepsis. Am Surg 67 (3): 253-255; discussion 255-256, 2001.

29. Lin E, Lowry SF, Calvano SE. The systemic response to injury. Schwartz SI, Shires GT, Spencer FC, Daly JM, Fischer JE, Galloway AC (Eds). Principles of Surgery. 7th ed. 1999; (1): 3-51.

30. Hall-Angerås M, Säljö A, Hasselgren PO. Effect of methylprednisolone, indomethacin, and diethylcarbamazine on survival rate following trauma and sepsis in rats. Circulatory Shock 1986; 20 (3): 231-238.

31. Bone RC, Fisher CJ, Clemmer TP, Slotman GJ, Metz CA, Balk RA. A controlled clinical trial of high-dose methylprednisolone in the treatment of severe sepsis and septic shock. N Engl J Med 1987; 317 (11): 653-658.
32. Russell JA, Walley KR, Gordon AC. Interaction of vasopressin infusion, corticosteroid treatment, and mortality of septic shock. Crit Care Med 2009; 37 (3): 811-818.

33. Hack CE. Tissue factor pathway of coagulation in sepsis. Crit Care Med 2000; 28: 9: 25-30.

34. Fourrier F, Chopin C, Goudemand J et al. Septic shock, multiple organ failure, and disseminated intravascular coaguation. compared patterns of antithrombin III, protein C, and protein S deficiencies. Chest 1992; 101 (3): 816-823.

35. Mesters RM, Mannucci PM, Coppola R, Keller T, Ostermann H, Kienast J. Factor VIIa and antithrombin III activity during severe sepsis and septic shock in neutropenic patients. Blood 1996; 88 (3): 881-886.

36. Gando S, Kameue T, Nanzaki S, Nakanishi Y. Disseminated intravascular coagulation is a frequent complication of systemic inflammatory response syndrome. Thrombosis Haemostasis 1996; 75 (2): 224-228.

37. Lorente JA, García-Frade LJ, Landín L et al. Time course of hemostatic abnormalities in sepsis and its relation to outcome. Chest 1993: 103 (5): 1536-1542.

38. Maki DG. Microbiologic diagnosis of blood culture-negative sepsis by hemofiltration. Crit Care Med 2004; 32 (4): 1075-1077.

39. Cunningham AJ. Acute respiratory distress syndrome- two decades later. Yale J Biol Med 1991; 64 (4): 387-402

40. Salkowski C, Detore G, Franks A, Falk M, Vogel SN. Pulmonary and hepatic gene expression following cecal ligation and puncture: Monophosphorly lipid A prophylaxis attenuetes sepsis-induced cytokine and chemokine expression and neutrophil infiltration. Infect Immun 1988; 66 (8): 3569-3578.

41. Browder W, Ha T, Chuanfu L, Kalbflesch JH, Ferguson DA, Williams DL. Early activation of pulmonary nuclear factor $\mathrm{\kappa B}$ and nuclear factor interleukin-6 in polymicrobial sepsis. J Trauma Injury 1999; 46 (4): 590-596.

42. Ksenzenko S, Davidson S, Saba A et al. Effect of triiodotironine augmentation on rat lung sulfactant phospfolipids during sepsis. J Appl Physiol 1997; 82 (6): 2020-2027.

43. Raafat A, Franko A, Zafar R, Dulchavsky S, Diebel LN, Ksenzenko S. Effect of thyroid hormone (T3) responsive changes in sulfactant apoproteins on sulfactant function during sepsis. J Trauma1997; 42 (5): 803-809.

44. Wang P, Ba ZF, Chaudry IH. Mechanism of hepatocellular dysfunction during early sepsis: Key role of increased gene expression and release of proinflammatory cytokines tumor necrosis factor and interleukin-6. Arch Surg 1997; 132 (4): 364-369.

45. Koo DJ, Chaudry IH, Wang P. Kupffer cells are responsible for producing inflammatory cytokines and hepatocellular dysfunction during early sepsis. J Surg Res 1999. 83 (2): 151-157.

46. Gloor B, Uhl W, Tcholakov O, Roggo A, Müller CA, Worni M, Büchler MW. Hydrocortisone treatment of early SIRS in acute experimental pancreatitis. Digestive Dis Sci 2001; 46 (10): 2154-2161.

47. Nagaya T, Fujieda M, Otsuka G, Yang JP, Okamoto T, Seo H. A potential role of activated NF-kappa $b$ in the pathogenesis of euthyroid sick syndrome. J Clin Invest 2000; 106 (3): 393-402.

48. Yang ZL, Yang LY, Huang GW, Liu HL. Triiodothyronine supplement protects gut barrier in septic rats. World J Gastroenterol 2003; 9 (2): 347-350.

49. Baue A, Günther B, Hartl W, Ackenheil M, Heberer G. Altered Hormonal activity in severely ill patients after injury or sepsis. Arch Surg 1984; 119 (10): 1125-1132.

Received April 30, 2010. Accepted February 20, 2012. 